\title{
Mechanism of Diamond-Like Carbon (DLC) Delamination under Rolling Contact Condition
}

\author{
Tsutomu Sato ${ }^{*}$, Tsuyoshi Saito and Shinji Fujita \\ Basic Technology Research Center, NSK Ltd. \\ 1-5-50 Kugenuma Shinmei, Fujisawa-shi, Kanagawa 251-8501, Japan \\ *Corresponding author: sato-ts@nsk.com \\ ( Manuscript received 11 July 2008; accepted 28 October 2008; published 15 November 2008 ) \\ ( Presented at JAST Tribology Conference Tokyo, May 2008 )
}

\begin{abstract}
Diamond-like carbon (DLC) is being advanced as an excellent surface modification technology for a growing number of applications because of its low friction coefficient and excellent wear resistance. Due to the excellent characteristics of certain mechanical elements, such as a bearing, high levels of functionality are expected. Unfortunately, it is difficult to take full advantage of such high functionality because of insufficient endurance under high-pressure operating conditions. In order to make use of DLC as a bearing surface coating, the mechanism of DLC delamination under high-pressure conditions needs to be clarified. This paper discusses the mechanism of delamination of the intermediate layer of a DLC coating on a bearing in a test rig and by numerical simulation using FEM analysis. Test results revealed that the smaller the Young's modulus value of the intermediate layer (a factor affecting durability) of the DLC coating, the greater the resistance to delamination.
\end{abstract}

Keywords: tribology, diamond-like carbon, rolling contact, delamination, bearing, finite element method

\section{Introduction}

DLC coatings are being used in an ever-expanding range of applications because of the technology's low-friction, seizure-resistant, and wear-resistance qualities. However, the durability of DLC coatings remains inadequate, which hinders practical use of such technology for applications, including bearings, operating under high-pressure conditions. Although the performance of DLC coatings has been evaluated for durability under rolling contact ${ }^{1)}$, and has been evaluated as a surface coating for bearings ${ }^{2,3)}$ and gears ${ }^{4)}$, there are very few examples where delamination of DLC coatings have been seriously investigated ${ }^{5)}$.

In this paper, we have evaluated the delamination pattern and the endurance of DLC coatings with varying degrees of adhesion, and analyzed stress in DLC coatings under rolling contact conditions using FEM analysis. Investigative results of the delamination mechanism of DLC coatings are also reported.

\section{Specimen}

First the chromium composite layer, then the intermediate layer, and finally the carbon layer of the DLC coatings used for this evaluation were formed on a
JIS SUJ2 base material using the unbalanced magnetron sputtering (UBMS) method (see Fig. 1). Table 1 lists the properties of the intermediate layer, and shows differing degrees of hardness and Young's modulus values after changing certain elements. The Young's modulus of each specimen's intermediate layer, which was determined by nanoindentation, were obtained from loading/unloading curves during push-out testing, and

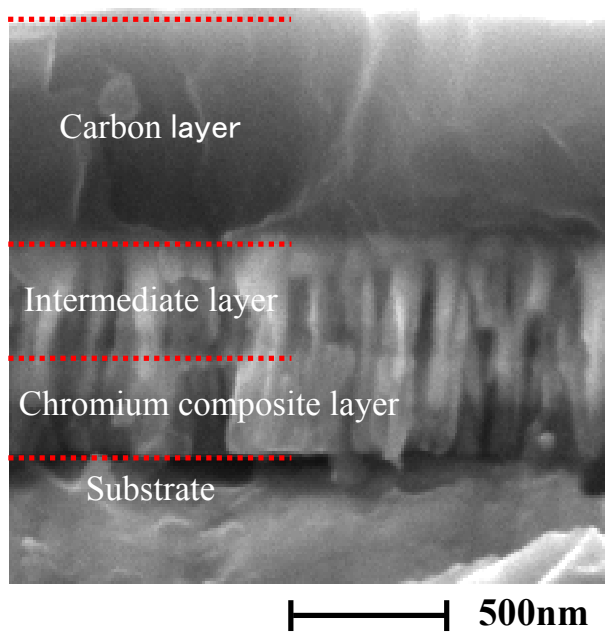

Fig.1 Cross-section view of a DLC coating (SEM micrograph) 
Table 2 Intermediate layer properties

\begin{tabular}{ccc}
\hline & DLC1 & DLC2 \\
\hline Element & W,C & Si,C \\
Thickness $(\mu \mathrm{m})$ & 0.5 & 0.5 \\
Young modules $(\mathrm{GPa})$ & 340 & 240 \\
Hardness $(\mathrm{GPa})$ & 32 & 24 \\
\hline
\end{tabular}

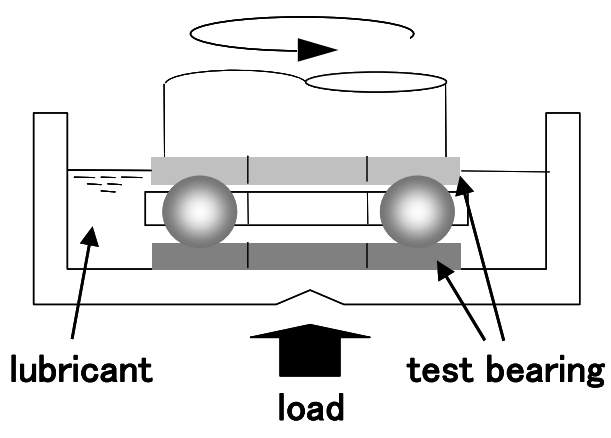

Fig.2 Thrust bearing endurance test rig

Table 1 Bearing test conditions

\begin{tabular}{c|c} 
Test bearing & 51305 \\
\hline Rotating speed $\left(\mathrm{min}^{-1}\right)$ & 2500 \\
\hline Maximum contact stress $(\mathrm{GPa})$ & 3.6 \\
\hline Lubrication method & Oil bath \\
\hline Lubricant & VG68
\end{tabular}

by interrupting the formation of DLC coating layers at the intermediate layer stage; thus the intermediate stage actually becomes the top layer.The hardness and Young's modulus of Carbon layer are $25 \mathrm{GPa}$ and 190 $\mathrm{GPa}$, respectively.

\section{Testing method}

\subsection{Scratch test}

Scratch tests were carried out to evaluate adhesiveness. Critical loading was calculated by changes in tangential force and surface observation after testing using a diamond indenter with of a point radius of $0.05 \mathrm{~mm}$ and an included angle of $90^{\circ}$.

\subsection{Endurance test using thrust bearing}

Endurance testing of DLC coatings was carried out under rolling contact conditions by applying a DLC coating to the raceway shaft washer and housing washer of a thrust ball bearing (51305). The test machine is illustrated in Fig. 2, and test conditions are listed in Table 2. Using an acceleration sensor, testing was interrupted when the vibration value exceeded a certain value to determine visually whether or not delamination of the DLC coating occurred. Testing was stopped if there was any delamination; otherwise testing continued.

\section{Test results}

\subsection{Results of scratch test}

Fig. 3 shows scratch test results, and Fig. 4 shows an optical micrograph of the post-testing surface. Critical load was $4.8 \mathrm{~N}$ for DLC1, and 7.3 N for DLC2. Scratch test results revealed that DLC coating adhesiveness was superior for DLC2 compared to that of DLC1.

\subsection{Delamination pattern of coating under rolling contact conditions}

In order to investigate the delamination pattern under rolling contact conditions, we continued bearing testing even after the occurrence of delamination, and observed a temporal change of DLC coating delamination. Optical micrographs in Fig. 5 show the change in DLC coating delamination over time for DLC1. The gradual progression of delamination over time occurred throughout the traction surface area. Results of element analysis (see Fig. 6) detected

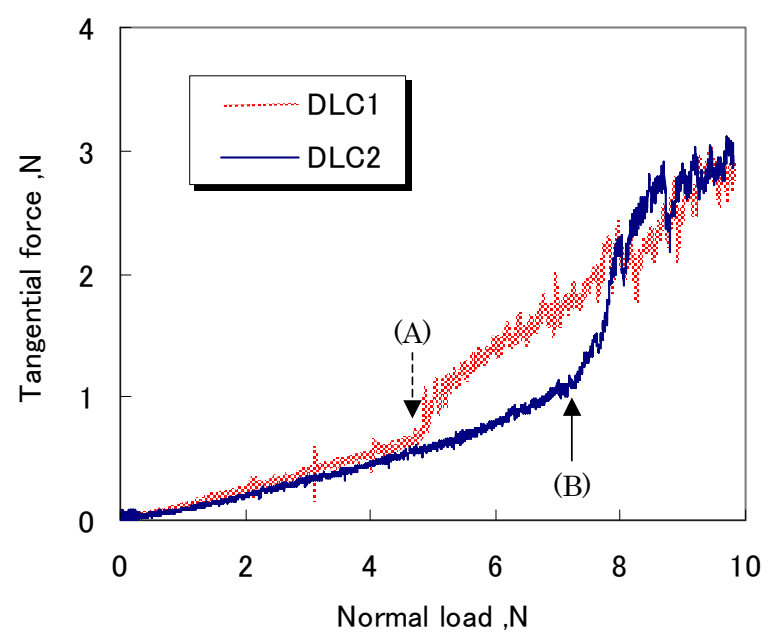

Fig.3 Scratch test results
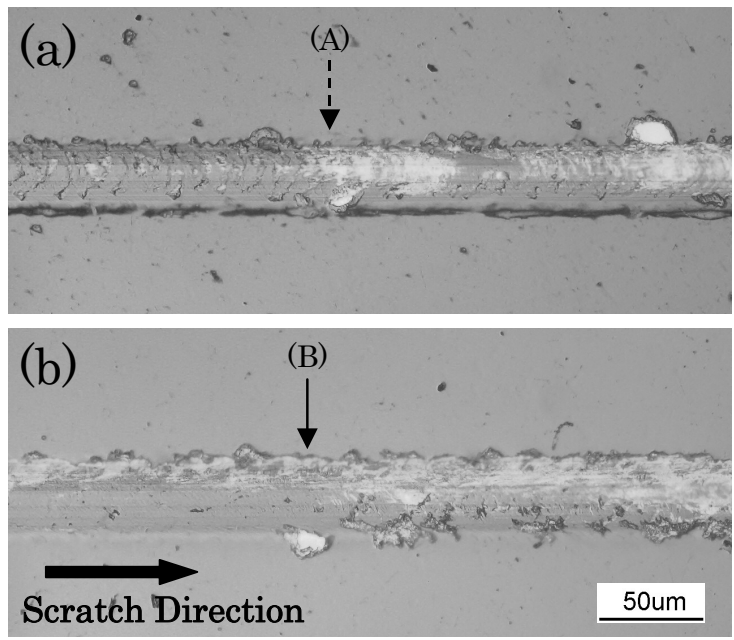

Fig.4 Micrographs showing trace of critical loading on (a) DLC1 and (b) DLC2 (optical microscope) 

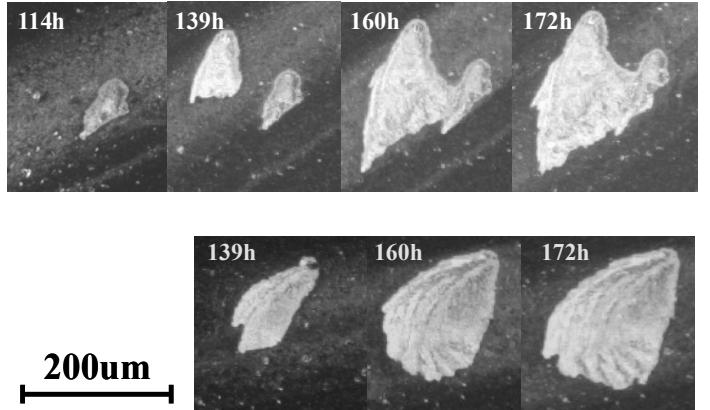

Fig.5 Micrographs of change in DLC coating delamination overtime (optical microscope)
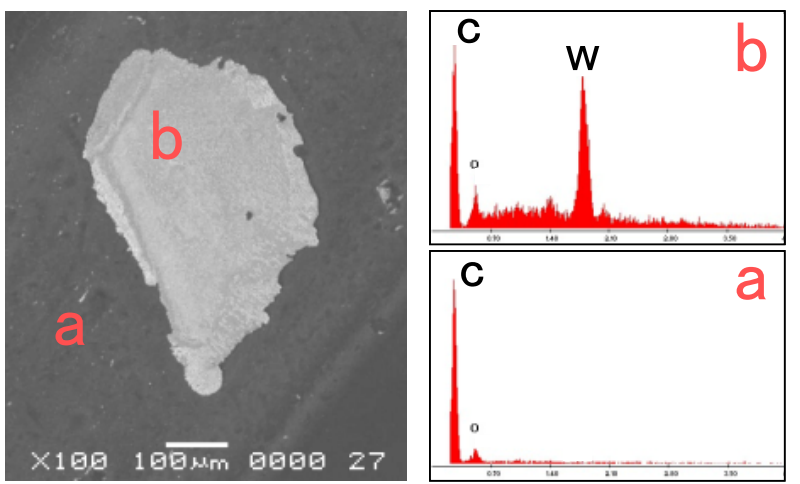

Fig.6 Element analysis results of DLC coating delamination

elements $\mathrm{W}$ and $\mathrm{C}$ in the surface of the delaminated area, which suggests that the delamination originated at the intermediate layer or the interface between carbon and intermediate layer. Elements making the intermediate layer were also detected in DLC2 as well as of DLC1.

\subsection{Delamination resistance bearing test}

Fig. 7 shows thrust bearing test results, and Fig. 8 shows and micrographs of the raceway surface after testing. L10 life of DLC1 was $\mathrm{L}_{10}=3.1 \times 10^{6} \mathrm{rev}$, and that of DLC2 was $\mathrm{L}_{10}=2.1 \times 10^{7} \mathrm{rev}$, which reveals that DLC2 is superior to DLC1 in durability. Furthermore, DLC2 was more resistant against delamination than DLC1 was.

\section{Discussion}

The test results described above revealed that the ability of a DLC coating to resist delamination under rolling contact conditions depends on specific elements that constitute the intermediate layer. Likely factors that affect the ability of a DLC coating to resist delamination include Young's modulus, crystal structure, residual stress, etc. Among these factors, the role of Young's modulus is exceptional in that it determines the ability of a base material to resist deformation, as described in reference 6 . Therefore, we calculated changes in stress levels acting on the DLC coating using FEM analysis and varying Young's modulus for the intermediate layer

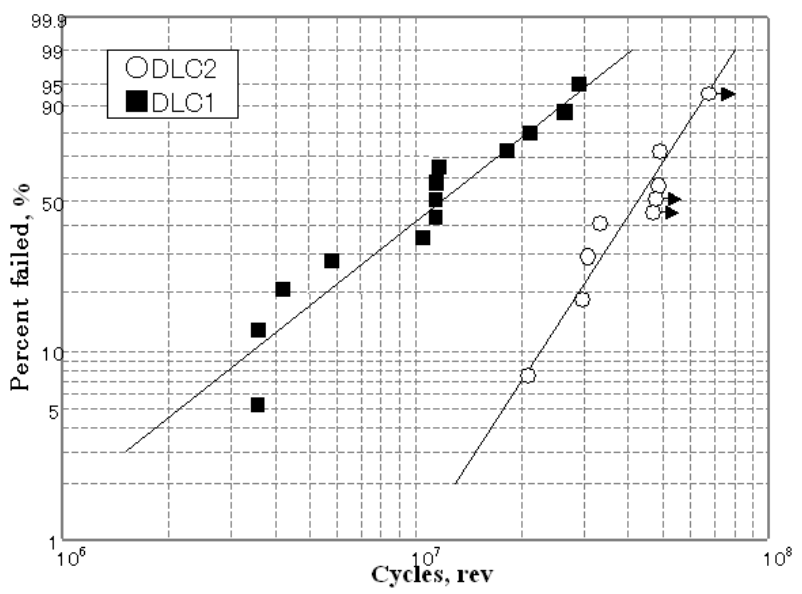

Fig.7 Thrust bearing test results showing delamination resistance of DLC coatings

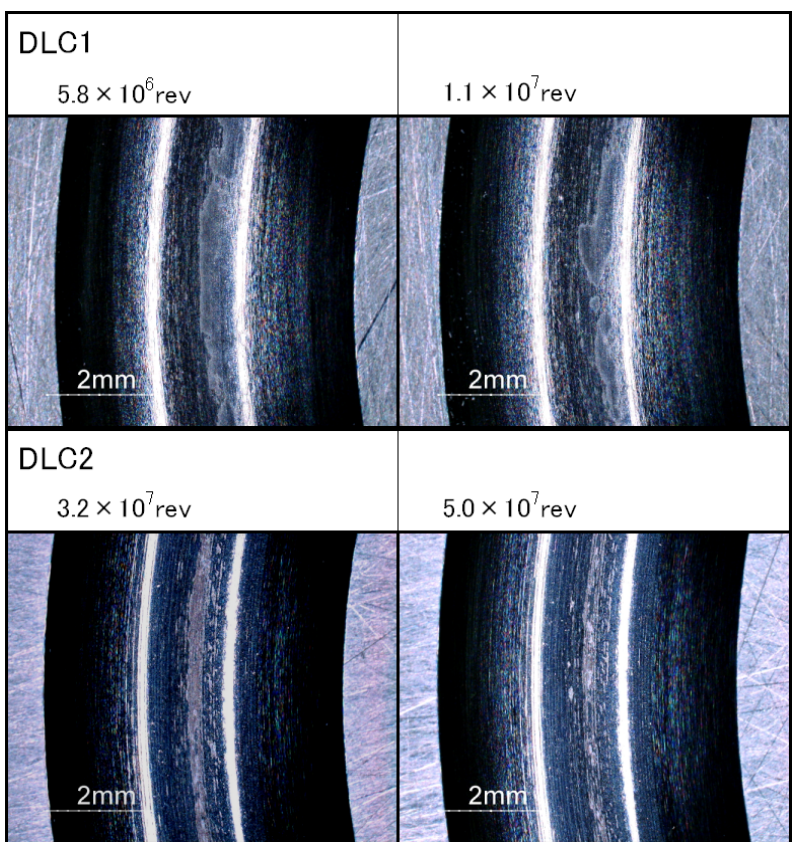

Fig.8 Micrographs of raceway surface after testing (optical microscope)

under rolling contact conditions.

5.1. Calculation model of internal stress by FEM analysis

Fig. 9 provides an illustration of the FEM analysis model. Three layers of thin coatings (layers 1, 2, and 3) were formed on a substrate. The top layer, layer 1 , is directly subjected to roller contact, vertical loading, and rolling-sliding motion. Stress levels were analyzed for three conditions using a cylindrical roller: loading only; loading followed by pure rolling motion; and loading followed pure sliding motion. Maximum compression stress for the $\mathrm{X}$ axis was defined as $\sigma_{x c}$; maximum compression stress for the $\mathrm{Y}$ axis was defined as $\sigma_{y c}$; maximum tensile stress for the $\mathrm{Y}$ axis was defined as $\sigma_{y t}$; and maximum shearing stress at a $45^{\circ}$ angle in the $X Y$ plane was defined as $\tau_{x y}$. 


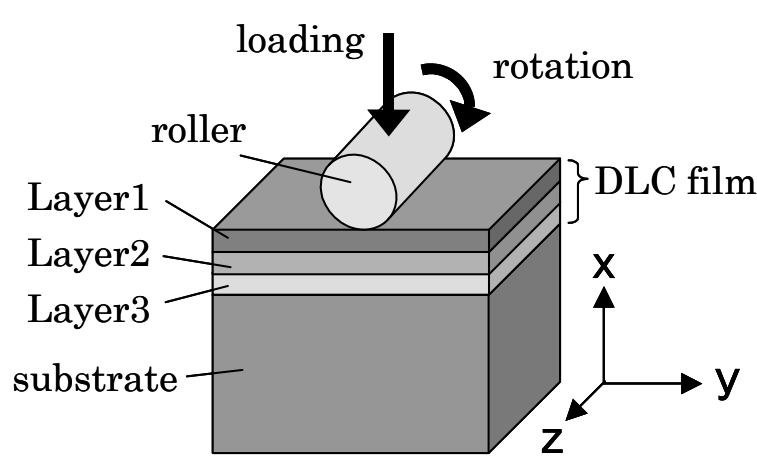

Fig.9 FEM analysis model

Table 3 FEM analysis parameters

\begin{tabular}{ccccc}
\hline & roller & substrate & Layer1,3 & Layer2 \\
\hline Thickness $(\mu \mathrm{m})$ & - & - & 0.5 & 0.5 \\
$\begin{array}{c}\text { Young's modulus } \\
(\mathrm{GPa})\end{array}$ & 208 & 208 & 208 & $100 \sim 340$ \\
$\begin{array}{c}\text { Poisson ratio } \\
\text { Pois }\end{array}$ & 0.3 & 0.3 & 0.3 & 0.3 \\
\hline
\end{tabular}

Table 3 lists the parameters used for calculation. In addition, roller load was $4 \mathrm{GPa}$ for imposing a maximum contact surface pressure, and the rotating angle of rolling-sliding motion was $5^{\circ}$. Assumptions include adhesion between the DLC coating layers, adhesion between the substrate and layer 3, contact between layer 1 and the roller, and a 0.1 friction coefficient for the contact surface.

\subsection{Analysis results}

Fig. 10 shows the calculation results of stress acting on layer 2 after changing the Young's modulus of layer 2 and applying load. The larger the Young's modulus of layer 2, the larger the absolute values of $\sigma_{y c}, \sigma_{y t}$, and $\tau_{x y}$. Accordingly, since layer 2 has to confirm to a deformation of the base material, the larger the Young's modulus, the larger the stress that is generated. Fig. 11 shows the results of applying rolling motion after loading. As shown in Fig. 11, under pure rolling motion conditions, the stress of Fig. 11 hardly changed compared with Fig. 10.

Fig. 12 shows the results of applying sliding motion after loading. Thus, as sliding was generated, $\sigma_{y}$ increased in both tensile and compression- $\sigma_{y t}$, especially, increased by more than twofold. Accordingly, friction force was likely generated on the surface of the thin coating due to sliding that was generated between the roller and layer 1. Thus, the larger the Young's modulus of layer 2, the larger the increment.

5.3. Review of delamination mechanism under rolling contact conditions

Based on the analysis results above, it is clear that higher the Young's modulus of a layer, and the generation of sliding on the contact surface, result in greater stress generation inside the coating. These

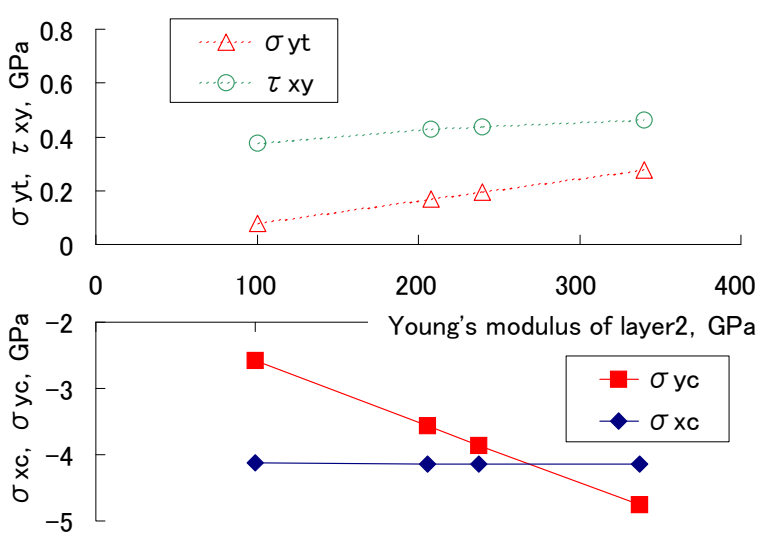

Fig.10 Maximum stress of layer2 (applying load)

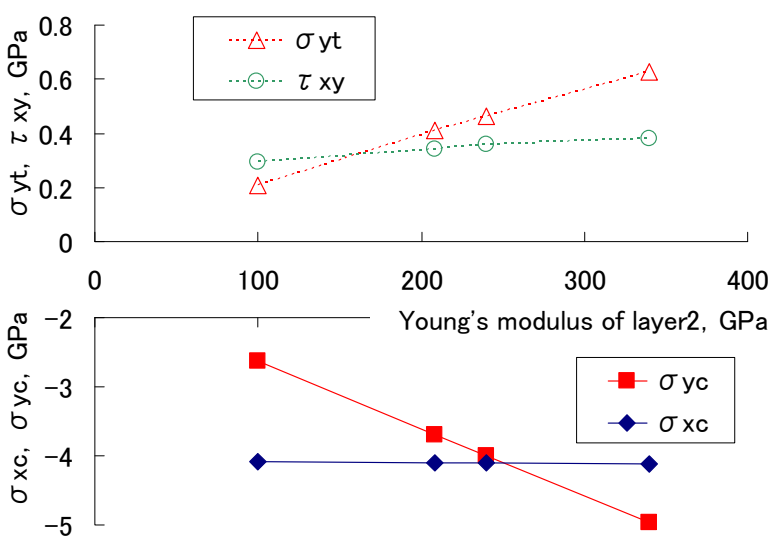

Fig.11 Maximum stress of layer2 (applying rolling motion after loading)

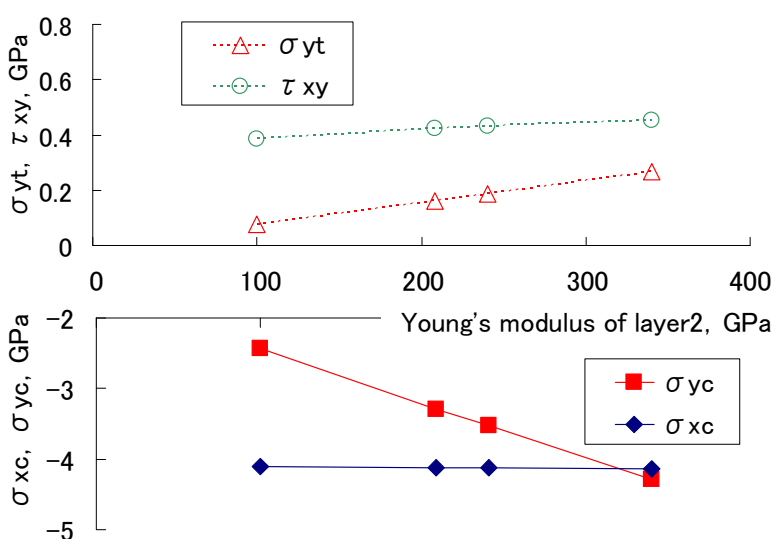

Fig.12 Maximum stress of layer2 (applying sliding motion after loading)

results are consistent with our test results where the Young's modulus of the intermediate layer for DLC2 was superior in durability qualitatively. Therefore, under rolling contact conditions, it is assumed that the smaller the Young's modulus, the better the durability.

However, it is not clear yet which stress causes the delamination of DLC coatings under rolling contact conditions. If DLC coating delamination is the same phenomenon as that of material rolling fatigue, the 
delamination is caused by the maximum shearing stress $\tau_{x y}$, and rolling fatigue life $L$ is dependent upon the maximum shearing stress $\tau_{x y}$, which would then satisfy the following formula or a formula that considers residual stress ${ }^{7}$.

$$
L \propto\left(\frac{1}{\tau_{x y}}\right)^{9}
$$

Life test results of DLC1 and DLC2 showed a sevenfold difference. However, the theoretical life ratio calculated using the formula above (1) with $\tau_{x y}$ obtained from FEM analysis was about 1.7. The difference between these values is quite different. Therefore, we assume that the stress causing delamination of a coating is not $\tau_{x y}$, but rather $\sigma_{y}$, which varies remarkably according to the Young's modulus of the intermediate layer.

\section{Conclusion}

The following information was obtained from bearing endurance test results and FEM analysis calculations of stress acting on the DLC coating interior:

(1) Different elements that constitute the intermediate layer play a significant role in varying degrees of resistance against delamination under rolling contact conditions. Also, coating delamination originated from the intermediate layer and gradually progressed with the passage of time.

(2) Numeric simulations using FEM analysis revealed that the higher the Young's modulus of layer 2, the greater the influence of $\sigma_{y c}$ and $\sigma_{y t}$ on layer 2. Under pure sliding conditions, $\sigma_{y t}$ increased by more than twofold.

(3) In order to improve the delamination resistance of
DLC coatings, a lower Young's modulus of the intermediate layer is preferable.

\section{References}

[1] Hayashida, K., "Tribological Properties of DLC Coatings in Rolling Contacts," J. Jpn. Soc. Tribol., 47, 2002, 840-845. (in Japanese)

[2] Olofsson, U., Sjostrom, H. and Sjodin, U., "Increased Wear Resistance of Rolling Bearings Using Me-C:H Coating Rollers," Transaction of the ASME Journal of Tribology, 122, 2000, 682-688.

[3] Doll, G. L., "Improving the Performance of Rolling Element Bearings with Nanocomposite Tribological Coatings," Annual Technical Conference Proceedings Society of Vacuum Coaters, 49, 2006, 580-588.

[4] Kalin, M. and Vizintin, J., "The Tribological Performance of DLC-Coated Gears Lubricated with Biodegradable Oil in Various Pinion/Gear Material Combinations," Wear, 259, 2005, 1270-1280.

[5] Jianga, J. C., Meng, W. J., Evans, A. G. and Cooper, C. V., "Structure and Mechanics of W-DLC Coated Spur Gears," Surface and Coatings Technology, 176, 2003, 50-56.

[6] Kinno, D. and Saitou, T., "Korogarisesshoku ni okeru DLCmaku no hakuritaikyuusei ni oyobosu himakubussei no eikyou," Proc. JAST Tribol. Conf., Tokyo, 2004, 301-302. (in Japanese)

[7] Zaretsky, E. V., Parker, R. J., Anderson, W. J. and Miller, S. T., "Effect of Component Differential Hardness on Residual Stress and Rolling-Contact Fatigue," NASA TN D-2664, 1965. 